\title{
Quantitative Determination of Tritium in Metals and Oxides
}

\author{
D. E. Vance \\ M. E. Smith \\ G. R. Wraterbury
}

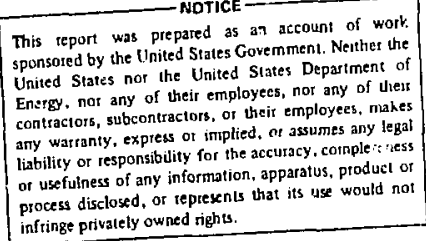




\title{
QUANTITATIVE DETERMINATION OF TRITIUM IN METALS AND OXIDES
}

\author{
by
}

\author{
D. E. Vance, M. E. Smith, and G. R. Waterbury
}

\begin{abstract}
Metallic samples are analyzed for tritium by heating the sample at $1225 \mathrm{~K}$ in a moist oxygen stream. The volatile products are trapped and the tritium is quantitatively determined by scintillation spectroscopy. The method is used to determine less than 1 ppb of tritium in 100-mg samples of lithium, iron, nickel, cerium, plutonium, and plutonium dioxide. Analysis of 18 cuts of a tritium-zirconium, copper foil "standard" over a 3-yr period showed a tritium content of $45 \mathrm{ppm}$ and a standard deviation of $6 \mathrm{ppm}$.
\end{abstract}

\section{INTRODUCTION}

The amount of tritium in lithium laser-fusion reactor fuel and in the fuel-preparation materials was of concern in the fuel development programs. In addition, the amount of tritium in plutonium and plutonium dioxide must be known to metallurgically process them. We adapted the method for tritium analysis in hot cells reported by MacDougall et ai. ${ }^{1}$ for use with these materials.

Without the complications caused by the hot cell, the method is much simpler. The humidifying jar (Fig. 1) is at room temperature. The reaction furnace tube (Fig. 2) is combined with the oxidation furnace tube and is heated with a commercial resistance furnace. The short plumbing permits reduction of the reaction time to $30 \mathrm{~min}$. We eliminate the spiral trap used by MacDougall and collect the sample by bubbling the carrier gas $\left(\mathrm{O}_{2}\right)$ through an ice-cooled volumetric flask filled with distilled water.

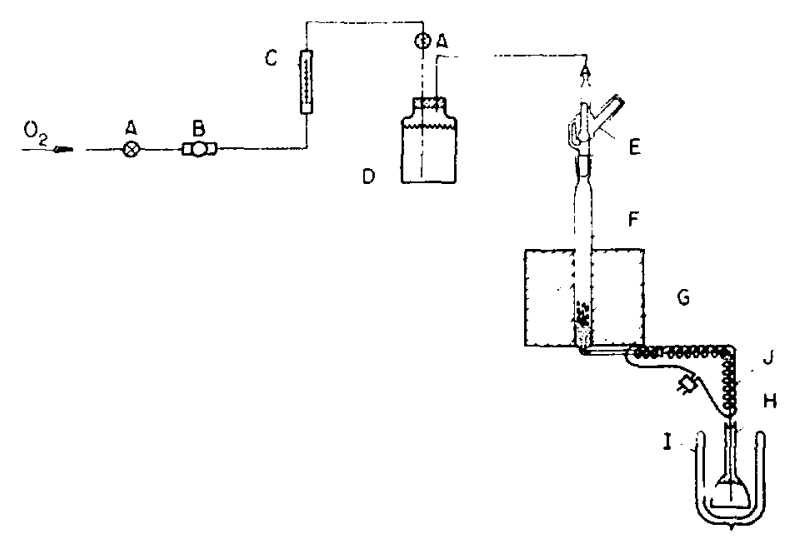

Fig. 1.

Combustion apparatus. A, Hoke valves; $B$, needle value; $C$, rotometer; $D$, humidifying (Mason) jar; $E$, sainple dropper; $F$, furnace tube; $G$, resistance furnace; $H$, collection flask; $I$, dewar; $J$, heating tape. 


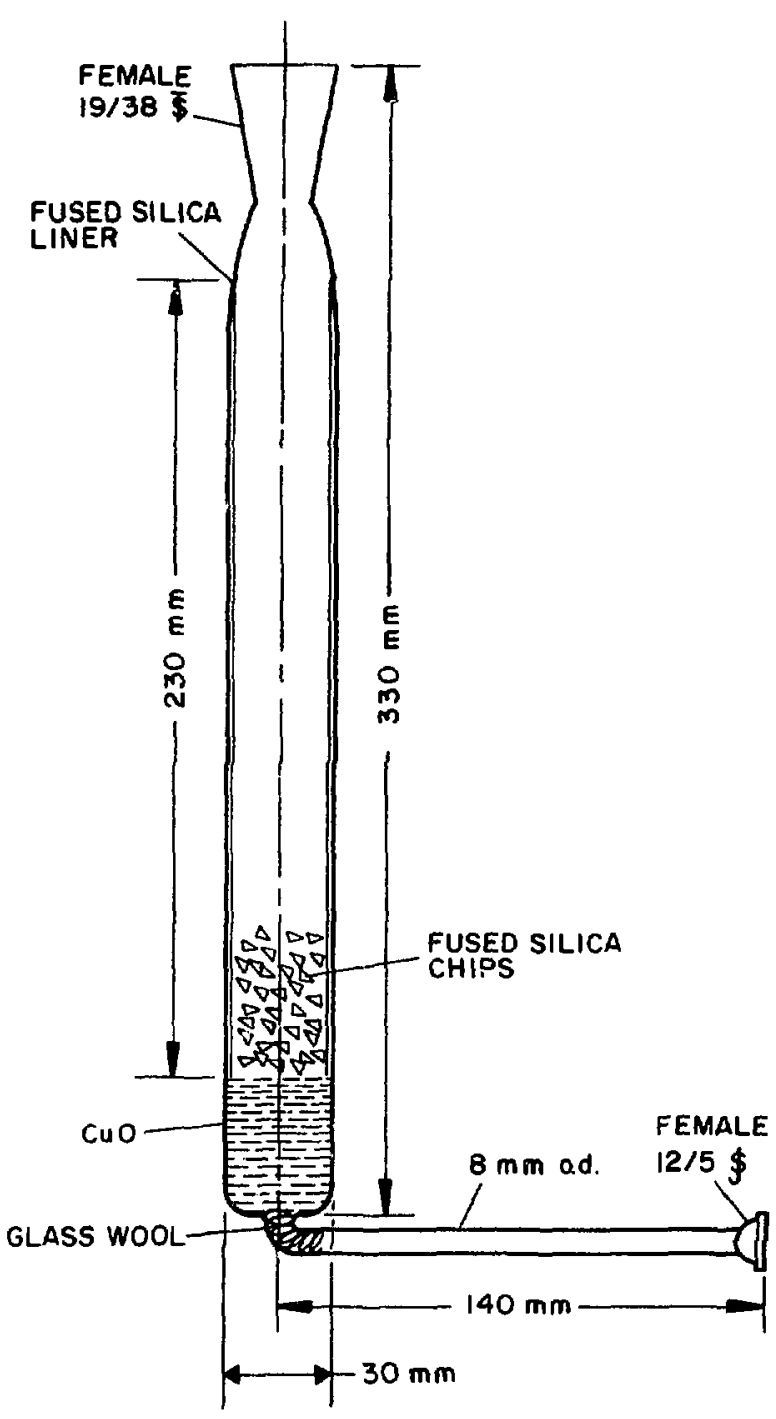

Fig. 2.

Fused silica furnace tube.

\section{APPARATUS AND REAGENTS}

\section{A. Apparatus}

Balance: Ainsworth Model BCT or equivalent.

Dewar: of suitable dimensions to enclose a $100-\mathrm{ml}$ volumetric flask, two required.

Flask: 100-ml volumetric, three required for each analysis.
Furnace Tube: fused silica (Fig. 2).

Gloved Enclosure: suitable for handling plutonium. Only the reaction furnace tube and sample dropper are in this enclosure.

Heating Tape: Briscoe iManufacturing Co. or equivalent, one required to heat the exit tube from the furnace tube to the collection flask.

Inert Atmosphere Enclosure: similar to that described by Smith et al. ${ }^{2}$

Liquid Scintillation Spectrometer: Packard TriCarb Model 2001 or equivalent.

Miason Jar: 1-qt or equivalent, fitted with twohole rubber stopper.

Pipette: $10-\mu \ell$ disposable, Microcap, Drummond Scientific Co. or equivalent, nine required for each analysis.

Pipette: 5-m $\ell$, one required.

Resistance Furnace: 8-in.. Electro-Applications, Inc. or equivalent.

Rotometer: Hoke Bantam or equivalent, 0 to 0.75 $\ell /$ min oxygen.

Sample Dropper: borosilicate glass (Fig. 3).

Thermocouple: 0 to $1000^{\circ} \mathrm{C}$, with pyrometer, one required to monitor the temperature of the resistance furnace and furnace tube.

Tin Capsules: Laboratory Equipment Corp. No. 501-059 or equiva!ent.

Tubing: 1/4-in. copper, for connecting the oxygen supply, the humidifying (Mason) jar, and the sample dropper (Fig. 1).

Tubing: 1/8-in. stainless steel, for connecting the furnace tube and the collection flask (Fig. 1).

Ultrasonic Cleaner: optional. 


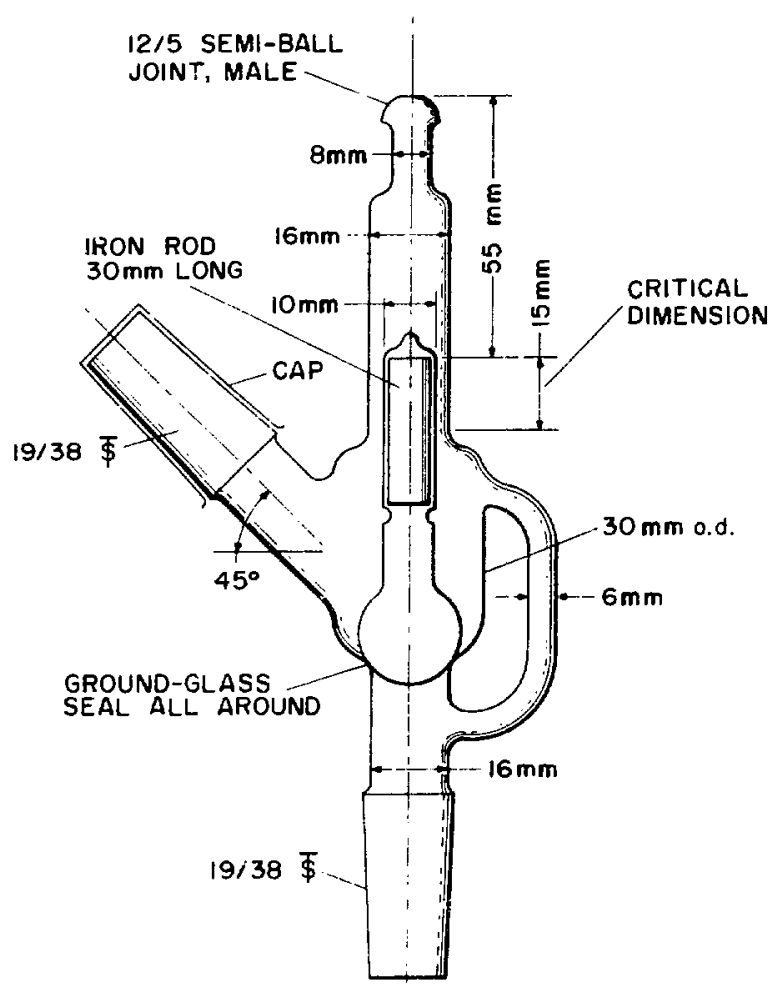

Fig. 3.

Sample dropper.

Valve: Hoke No. 4551Q4M or equivalent, two required.

Valve: needle, Robbins Aviation, Inc. No. INSG103-1P or equivalent, one required.

Variable Transformer: one required to control the temperature of the resistance furnace and one required for the heating tape on the exit tube.

Vial: scintillation, nine ! equired for each analysis.

\section{B. Reagents}

Cupric Oxide: wire form, reagent grade.

Grease: silicone, for sealing the ground-glass joints on the furnace tube and the sample dropper.
Ice: chipped.

Liquid Scintillation Cocktail: Aquasol, New England Nuclear or equivalent.

Oxygen: tank.

Reference Material: tritiated water, certified (ICN Pharmaceuticals, Inc.); used to determine the counting efficiency of the liquid scintillation spectrometer.

Reference Material: tritium-zirconium, copper foil-backed evaporated target, Oak Ridge National Laboratory or equivalent; used to ensure proper functioning of the combustion apparatus.

\section{SAMPLE PREPARATION}

Caution: Health and safety rules for handling radioactive materials including tritium must be rigidly followed, and adequate protection for the operator must be ensured with suitable gloved enclosures, fume hoods, protective clothing, and radiation monitoring equipment.

The weighed samples of lithium fuel and fuelpreparation materials are normally received packed in 1-dram vials within a sealed brass container. The atmosphere in the brass container is contaminated with tritium, and therefore the container must be opened in a suitable fume hood with tritium monitoring equipment available. The normal sample size required for each analysis is less than $50 \mathrm{mg}$ of lithium or approxinately $100 \mathrm{mg}$ of tritium-getter alloy. Smaller samples are used if he tritium concentration is greater than $1 \mathrm{ppm}$. Other materials submitted for tritium analysis are stored and cut into $100-\mathrm{mg}$ pieces in an inert atmosphere. Small pieces of samples and powders are loaded into tin capsules before analysis. (The amount of tritium in the tin capsules is negligible).

\section{SAMPLE ANALYSIS}

(1) At all times, the resistance furnace (Fig. 1) is kept at $1225 \mathrm{~K}$ and the heating tape at $425 \mathrm{~K}$. The humidifying jar is kept filled with water. 
(2) Before each day's analyses, the apparatus is flushed for at least $30 \mathrm{~min}$ by opening the Hoke valves and adjusting the needle valve until the rotometer registers an oxyen flow of $100 \mathrm{~m} / / \mathrm{min}$. This ensures a stable apparatus background for the analyses.

(3) While the apparatus is flushing, the necessary number of $100-\mathrm{m} \ell$ volumetric flasks are obtained (at least two for each analysis and one for the initial apparatus background). Each flask is rinsed with double distilled water then filled to the mark with double distilled water and shaken. Each flask is labeled with the number of the sample or blank to be collected in that llask.

(4) An initial aliquot (flask background) (see Sec. $V$ ) is taken from each flask and put into $15 \mathrm{m \ell}$ of scintillation cocktail in a scintillation vial. Each vial is labeled as the initial cut from a particular flask and shaken to ensure uniform mixing.

(5) The flasks for the first apparatus background (blank) and for the first sample are placed in the two dewars, and the dewars are filled with ice. The flasks are cooled for $30 \mathrm{~min}$ before the first blank is collected.

(6) The llask tor the first blank is positioned so that the exit tubing from the furnace tube is inside the flask and extends to within a few millimeters of the bottom of the flask. The eluted tritiated water is collected for $30 \mathrm{~min}$.

(7) At the end of the blank collection period, the collection flask is removed from the exit tubing, the tubing is wiped ciry, and the next flask is positioned on the exit tubing. 'The sample is placed in the sample dropper and dropped into the furnace tube.

(8) During this $30-\mathrm{min}$ sample collection period, the first flask is removed from the ice bath and replaced by the third flask.

(9) Two aliquots are taken from the collection flask of the first blank and put into separate scintillation vials each contuining $15 \mathrm{~m} \ell$ of scintillation cocktail.

(10) At the end of the sample collection period, the collection flasks are changed as in Step 7 above, and another blank is collected.

(11) During the collection period for the second blank, the sample collection flask is removed from the ice bath and replaced with the next sample collection flask. Two aliquots are taken from the sample collection flask.
(12) Steps 6 through 11 are repeated until all samples have been analyzed. The mixed scintillation vials are left overnight before counting to minimize oxygen-caused chemiluminescence.

(13) The tritium disintegration rate (count) of each scintillation vial is determined using a scintillation spectrometer adjusted to obtain the maximum counting efficiency for tritium.

(14) The average count for each sample is corrected for the flask background count and the apparatus background count.

(15) The amount of tritium in the original sample is given by the formulas

$$
\begin{aligned}
& \mu \mathrm{g} \mathrm{T}_{2}=\frac{4.633 \times 10^{-9}(\mathrm{C})(\mathrm{SF})}{(\mathrm{CT}) \frac{\mathrm{CE})}{(\mathrm{C})}} \\
& \mathrm{ppb} \mathrm{T}_{2}=\frac{4.633 \times 10^{3}(\mathrm{C})(\mathrm{SF})}{(\mathrm{CT})((\mathrm{E})(\mathrm{W})} .
\end{aligned}
$$

where $\mathrm{C}=$ corrected count,

$\mathrm{SF}=$ sampling factor to correct for only counting a fraction of the tritium reieased from each sample,

$\mathrm{CT}=$ counting time in minutes,

$\mathrm{CE}=$ counting efficiency in per cent, and

$\mathrm{W}=$ sample weight in milligrams.

\section{PROCEDURAL COMMENTS}

The normal aliquot size taken for scintillation counting, is $10 \mu \ell$ (sampling factor $10^{4}$ ), and the normal counting time is $5 \mathrm{~min}$. If the 5 -min count is $<1000$, the aliquot size is changed to $5 \mathrm{ml}$ (sampling factor $20 \%$. If a count of $9 \times 10^{\circ}$ for the $10-\mu \ell$ aliquot is obtained in $<0.50 \mathrm{~min}$, an aliquot from the collection flask is diluted $1: 10^{4}$, and duplicate $10-\mu \ell$ aliqurts of this are counted (sampling factor $10^{8}$ ).

When $10-\mu \ell$ aliquots are taken, the entire Microcap pipette is dropped into the scintillation cocktail. Each vial is then shaken, preferably in an ultrascnic cleaner, until all of the cloudy gel that formed in the pipette is replaced by clear liquid.

After each vial is loaded into the spectrometer counting chamber, our single-sample capacity requires a 30 -s wait before starting the spectrometer. Photoluminescence of the scintillation mixture will 
cause erroneous high readings if it is not allowed to decay for $30 \mathrm{~s}$.

The counting efficiency of the spectrometer is determined (and occasionally checked) by adding a 10- $\mu l$ aliquot of the tritiated water reference material to $15 \mathrm{~m} \ell$ of scintillation cocktail and counting it in the same manner as the samples. The 5-min count is compared mathemalically to the certified activity of the reference material to obtain the percentage of disintegrations counted by the spectrometer. The same brand of scintillation cocktail must be used for this determination as is used for the samples.

The limit of detection for this method as presently used is 0.01 pph, but this could be lowered by using more sophisticated counting techniques. The upper limit depends on selecting a practical sample size. The method applies to any material that is readily combustible or that will release tritium at $1225 \mathrm{~K}$.

\section{RELIABILITY}

We can only estinate the precision and accuracy of this method because we lack suitable reference materials. For six aliquots (10- $\mu l$ each) of a tritiated water reference material, the spectrometer counting efficiency was $45.8 \%$ with a standard deviation of $0.2 \%$. Eighteen cuts of the tritium-zirconium target reference material analyzed by the combustion method showed an average of $45 \mathrm{ppm} \mathrm{T}_{2}$ with a stan- dard deviation of $6 \mathrm{ppm}$. Eight cuts of the same tritium-zirconium target were anaiyzed by sealedtube dissolution and scintillation spectroscopy. The average tritium concentration was $42 \mathrm{ppm}$ with a standard deviation of $4 \mathrm{ppm}$, indicating no bias within the precision obtained.

\section{ACKNOWLEDGMENTS}

We are grateful for the sealed-tube dissolution and scintillation spectroscopy assistance provided by the Plutonium Assay and Radiochemistry Sections of the Los Alamos Scientific Laboratory Analytical Chemistry Group.

\section{REFERENCES}

1. C. S. MacDougall, T. K. Marshall, G. M. Matlack, and G. R. Waterbury, "Determination of Carbon. Hydrogen, and Tritium in Irradiated Reactor Fuels and Cladding Materials," Los Alamos Scientific Lahoratory report LA-5497 (May 1974).

2. M. E. Smith, J. M. Hansel, and G. R. Waterbury, "An Inert Atmosphere Enclosure for the Preparation of Samples Prior to the Determination of Oxygen," Los Alamos Scientific Laboratory report LA-3344 (August 1965). 